\title{
Characteristics of Ride-Sourcing usage for Shopping Trips in Bandung, Indonesia
}

\author{
Jeeten Kumar ${ }^{1}$ and Tri Basuki Joewono ${ }^{2, *}$ \\ ${ }^{1}$ Parahyangan Catholic University, Department of Civil Engineering, Jalan Ciumbuleuit 94, \\ Bandung, Indonesia, jeetenbhagnani@gmail.com \\ ${ }^{2}$ Parahyangan Catholic University, Department of Civil Engineering, Jalan Ciumbuleuit 94, \\ Bandung, Indonesia
}

\begin{abstract}
Shopping activities are an integral part of daily activities for people, and the growing existence of application-based transport mode, well known as ride-sourcing, gives an additional options. Ride-sourcing is believed to change travel behaviors of travelers especially for nonmandatory trips. As a relatively new mode, it is necessary to learn more about the ride-sourcing usage characteristics for shopping trips from experience in developing countries. This study aims to analyze the characteristics of ride-sourcing for shopping activities including the users. Data was collected using questionnaire distributed to households in Bandung City, West Java, Indonesia, and analyzed by employing binary logistic regression. Data shows that even ride-sourcing is famous, ride-sourcing is used as additional mode only and not as the primary mode for travel. Estimated model shows that the number of applications owned by users provide an ability for users to select shorter waiting time. Model also shows that travel charges become the most important reason in deciding the usage of ride-sourcing. This study reveals the fact that this application based service do not change fully the travelers' behavior.
\end{abstract}

\section{Introduction}

Studies report an evidence that shopping trips amounts to almost $20 \%$ of person's daily travels [1]. Even it is not mandatory trips, travels for shopping have a significant value to the travelers or even family. Before leaving for an in-store shopping trip, usually travelers considering many aspects, such as shopping location, type of store, distance to location, cost, includes the quality of the shop or market (along with their respective goods) [2]. Recker and Kostyniuk [23] stated that there are three hypotheses regarding the reason in selecting destination for the urban grocery shopping trips by individual shoppers, namely perception of the destination, accessibility to the destination, and relative number of opportunities.

As a prominent activity in daily life, shopping trips have a tight relationships with life style. It is not just to buy a thing, but it is completed as a part of entertainment or even trip chain. Thus, there are many external and internal factors influencing the behavior of shopping trips. It is also shaped by the advancing evolution of information and communication

\footnotetext{
* Corresponding author: vftribas@,unpar.ac.id
} 
technology (ICT). The evolution manifests in the shape of e-commerce or e-shopping. However, the emergence of ICT in shopping brings with it different travel behaviors [3]. Online shopping doesn't require consumers to be physically present in a shop in order to buy goods then the need for transportation can be ignored. As a consequences, in-store shopping trips can now be substituted or even completely eliminated when e-shopping was decided by shoppers. Essentially, shopping online decreases the frequency of shopping trips [3]. In spite of this, in-store shopping still remains inseparable from people daily activities because it also serves as social interaction, a leisure activity, and as part of a trip chain [4]. It is believed that in-store shopping will have a fans in the future, as shopping activities have a value that cannot be replaced by virtual activities. For example, the sensation to chat with shoppers face-toface is an important element.

Aside from its effects toward shopping activities, the emergence of ICT has also been found to affect conventional transportation and travel behavior. In developing conventional transportation systems, ICT acts as a hub that connects three vital transportation elements (facility, mode, and manpower) into a systematic data exchange network [5]. Utilizing ICT in existing transportation systems increases flexibility and efficiency, and disregards the need for new transportation infrastructure [6].

One of the many manifestations of ICT's use in transportation is ride-sourcing. Ridesourcing, due to its recent development, is still loosely defined. In some instances, ridesourcing is defined as a service that provides point-to-point transportation with a short waiting time [7]. A more comprehensive study defined ride-sourcing as a colloquially used term that describes a transportation service where vehicles that drop passengers are ordered and paid for through smartphone apps [8]. The California Public Utilities Commission narrows down the definition that the transportation service is provided through smartphone apps that connects passengers directly through to their drivers. These definitions help yield an idea that progress in ICT produces innovative services that fulfills transportation demand in real time [7].

At present in Indonesia, several companies provides platforms to connect the potential consumers with car drivers or motorcyclists in real time that can be accessed quite easy using smartphone application, namely Uber, Go-Jek, or Grab. The potential consumers access the platform using free downloaded application in smartphone to reach the drivers of noncommercial mode of transport. The application will inform the location using GPS and the request of potential consumers to the drivers. The drivers have a chance to accept the request or ignore it. When the drivers agree to take the order then he will send confirmation. The operator will inform the driver's decision to consumers including the estimated travel charge. In general, the charge was calculated based on distance traveled, peak or non-peak period, and the density of requests (demand) including its relation with the drivers' availability (supply). Brief discussion regarding the emergence of this internet-based shared transport services in Indonesia can be found in Susilo and Joewono [16].

Literature informs that ride-sourcing is used mainly for leisure activities [7], where this knowledge is built using evidence mostly from developed countries. As a fact, many aspects developed countries are different with developing countries. It requires an internet connection, an application in smartphone, and a particular amount of proficiency in using a smartphone [9] to generate a ride-sourcing trip. It is hypothesized there is a unique characteristics differentiate developed and developing countries in terms of the characteristics of users and ICT's infrastructure. Another possible aspect that differentiate is legal issue. Many developed countries refused to legalized ride-sourcing, while The Ministry of Transportation, Republic of Indonesia legalized the service by issuing a ministry regulation in 2017 using a name of 'Information Technology Based Application Providers' (Perusahaan/Lembaga penyedia aplikasi berbasis Teknologi Informasi). In fact, this regulation cannot satisfy all stakeholders up to today, as high tension is still appearing 
between conventional drivers and application-based drivers. With these issues, therefore, it is necessary to investigate the characteristics of usage and users of ride-sourcing using empirical evidence from developing countries. Very limited number of studies have investigated this issue in developing countries or Asia. One work from very limited number is the work of Medeiros et al. [17]. They discussed the effect of the merging between ICT and informal transport (ojeg) to travel behavior in Jakarta.

This study aims to explore the characteristics of the user and its usage using ride-sourcing to complete in-store shopping activity. This kind of study is useful for two reasons. Firstly, it could be used as a reference to identify the unique dynamism of ride-sourcing use in the region [10], where study using empirical evidence from developing countries or Asia is very rare at present. Secondly, it provides information for decision making process regarding the existence of ride-sourcing in developing countries, including Indonesia, whether it roles as complement or substitution. Therefore, this study may contribute to fill the gap in a growing body of research regarding application based transportation in developing countries.

\section{Data Collection}

\subsection{Materials}

Data for this study was collected by distributing questionnaire to households throughout the Bandung City. Bandung is the capital city of West Java province and located in the south of Jakarta, the capital city of Indonesia with a distance around $150 \mathrm{~km}$.

Questionnaire was distributed between 9th and 16th of June 2017. With a population amounted to 2,481,489 people [11], 520 questionnaires were distributed with the help of 26 surveyors. Each surveyor was required to explain the purpose of study to the respondents including explaining the meaning of the questions when there were questions. If the respondent was unable or refuse to writing down the answers, the surveyor assisted the respondent by reading out each question and filling in the answer. The procedure of data collection was illustrated in Fig. 1.

The response rate of this survey was more than $90 \%$, since the surveyors have approached the household at the time when the respondents available and having free time. Before the survey, all surveyors were provided with a briefing to ensure they will approach the family in proper and polite way. We also provided an appreciation for the time they spent. Since the survey were arranged to have a distribution in area and economic level of household, the surveyors were distributed accordingly. Thus, the surveyors should made a personal guess about the income level of the targeted household. In the time the guess was not confirmed, the surveyors should find another household until the designated sample size for each classification was satisfied. Thus, the survey was done using convenient sampling, as it was very difficult to have a perfect stratified random sampling.

The questionnaire consisted of 108 questions which was arranged into four parts, namely shopping location characteristics, traveler characteristics, ICT characteristics, and ridesourcing characteristics. In the part of ride-sourcing's questions, there was 12 questions of characteristics and 13 questions of perception regarding the quality of ride-sourcing's services. This article reported only the findings about ride-sourcing as a part of study by Joewono [12], while more detail discussion about ride-sourcing part is available in Kumar [13]. 


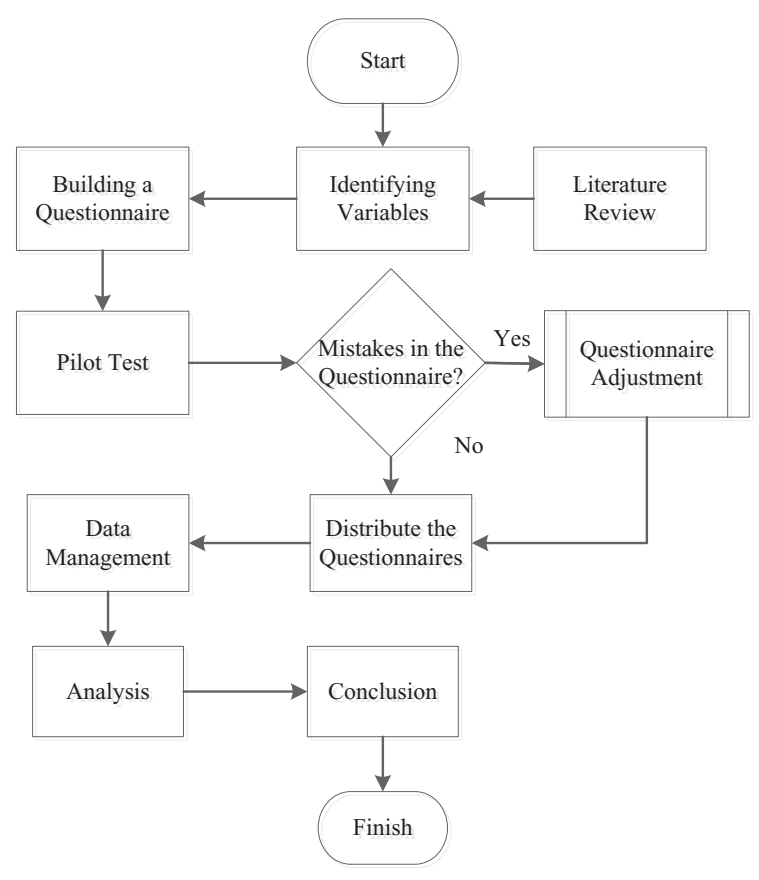

Fig. 1. Illustration of data collection process

\subsection{Descriptive Statistics}

Around $60 \%$ of the total respondents claimed as never used ride-sourcing for shopping trips in the last month. Around $40 \%$ reported at least once using ride-sourcing to reach shopping location. Almost $19 \%$ of respondents have used ride-sourcing at least 3 times in the last month. With this finding, only 205 out of 520 filled questionnaire can be used for further analyses.

Around $12 \%$ of the users stated as do not have any application (apps) in their smartphone. It revealed a fact that some users were helped by others to book the service. Around $42 \%$ of them stated as having one app. and 45\% having more than one app. Data shows that around $73 \%$ of users utilized ride-sourcing for shopping trips once a week while around $27 \%$ respondents used it more than once a week. In term of travel expenses using ride-sourcing, $65.5 \%$ of users spend 20,000 Rupiah per trip or less. Characteristics of the usage of ridesourcing are displayed in Table 1.

Most users experience a short waiting time when ordering the service, namely $96 \%$ of users required to wait 15 minutes or shorter. Almost half of respondents (47.8\%) experienced travel time of 16 to 30 minutes per trip and only $18.6 \%$ spent 31 to 45 minutes on the road using the service. Data also shows that the service is used to reach a quite close shopping location to their place of origin.

Furthermore, the characteristics of the users are presented in Table 2. Users of ride-sourcing come from a fairly even proportion of age, namely 24 years old or younger, 24 up to 40 years old, and 41 years old or older. Users are dominated by users with an age ranges from 24 up to 55 years old as much as $76 \%$. From the point of view of monthly income, users come from middle to lower group of community. Similar trend is found when observing the monthly expenditure. It also shows that the higher the income, the less likely they use ridesourcing to reach shopping location. 
Table 1. Characteristics of ride-sourcing usage for shopping trips

\begin{tabular}{llr}
\hline & Characteristics & Proportion (\%) \\
\hline Charges & $<10$ & 18.2 \\
Incurred & $10-20$ & 47.3 \\
(Thousand & $20-30$ & 22.2 \\
Rupiah) & $>30$ & 12.3 \\
\hline Trip & Once a week & 72.7 \\
Frequency & Twice a week & 11.7 \\
& More than twice a week & 15.2 \\
\hline Number of & No app. owned & 12.2 \\
Apps Owned & One app. & 42.4 \\
& Two or more apps. & 45.4 \\
\hline
\end{tabular}

Table 2. Characteristics of the users of ride-sourcing

\begin{tabular}{llr}
\hline & Characteristics & Proportion (\%) \\
\hline Age (Years) & $16-24$ & 16.6 \\
& $25-40$ & 41.0 \\
& $41-55$ & 35.0 \\
& $>55$ & 6.8 \\
\hline Family Income (Million & $<3$ & 20.0 \\
Rupiah per month) & $3-6$ & 31.0 \\
& $6-9$ & 17.1 \\
& $9-12$ & 8.1 \\
& $12-15$ & 7.6 \\
& $>15$ & 13.8 \\
\hline Family Expenditure & $<3$ & 39.5 \\
(Million Rupiah per & $3-6$ & 31.0 \\
Month) & $6-9$ & 13.3 \\
& $9-12$ & 7.6 \\
& $12-15$ & 3.3 \\
& $>15$ & 2.9 \\
\hline
\end{tabular}

Furthermore, the respondents were also requested to share their perception regarding the service quality of ride-sourcing when it was compared to conventional public transportation. The results are reported in Table 3. Table shows that ride-sourcing is more superior compared to conventional public transportation in all aspect of service. Ride-sourcing have highest positive perception in the aspect of easiness to use, as there is no need to wait in the bus stop or to transfer. Even ride-sourcing still have higher positive perception (around 63\%) in the aspect of fare, around $37 \%$ of users have perception that the price of this application-based transport mode is comparable with conventional one. The fare become the lowest positive perception among the 13 aspects of comparison. 
Table 3. Perception regarding the service of ride-sourcing

\begin{tabular}{lccc}
\hline Compared to conventional public transportation, the & \multicolumn{3}{c}{ Proportion (\%) } \\
\cline { 2 - 4 } service of ride-sourcing is ... & SA & A & N-SD \\
\hline Easier to be reached & 22.9 & 65.7 & 11.4 \\
Shorter waiting time & 16.4 & 65.7 & 17.9 \\
More suitable with lifestyle & 11.9 & 54.2 & 33.9 \\
More secure & 20.9 & 54.7 & 24.4 \\
More comfortable & 22.9 & 65.2 & 11.9 \\
Safer travel & 14.9 & 49.8 & 35.3 \\
Shorter travel time & 21.4 & 59.7 & 18.9 \\
Easier to pay & 19.9 & 56.2 & 23.9 \\
Cheaper & 13.4 & 49.8 & 36.8 \\
Having higher car quality & 19.9 & 60.7 & 19.4 \\
Having higher driving skill & 13.4 & 58.2 & 28.4 \\
Having more complete driver's identity & 21.9 & 54.7 & 23.4 \\
Easier to use & 32.8 & 59.2 & 8.0 \\
\hline
\end{tabular}

*SA=strongly agree, $\mathrm{A}=\mathrm{Agree}, \mathrm{N}-\mathrm{SD}=$ neutral up to strongly disagree

\section{Analyses}

Binary logistic regression is estimated to analyze the factors that determine the characteristics of the usage of ride-sourcing. In this study, travel time using ride-sourcing is selected as the proxy to explain the characteristic. It is interesting to know the significant variables that influence the decision to use ride-sourcing with long travel time. When users are still using ride-sourcing even in long travel time, it can be interpreted that the users are a big fan of ride-sourcing.

In this article, two models are reported. One model focuses on the variable that is believed to give a significant influence to users' decision. The other model incorporates socio demographic variables. The two models are compared to investigate the role of socio demographic characteristics of users in explaining the travel time.

\subsection{Model estimation without socio-demographic variables}

The first model estimates the parameters explaining the influencing factors of travel time as dependent variable. The result of estimation is presented in Table 3 . The Chi-square value of 44.557 along with very small significance value (below 0.01) implies the model improvement as a result of incorporating explaining variables. The goodness-of-fit test using Hosmer \& Lemeshow has a value of 0.613 , which is far above 0.05 , supports the idea that independent variables improve the model. Two values of $\mathrm{R}$-square from Nagelkerke and Cox \& Snell reveal the variability that can be predicted by the model. Result shows a value of 0.198 and 0.279 for Cox \& Snell R-square and Nagelkerke R-square, respectively. These values explains that the model have enough capability in explaining the variability. The percent correct of the model is amounted as much as $77.2 \%$, which implies a good prediction ability. From these statistics, it can be summarized that the model is good in explaining the dependent variable. 
Table 3. Parameter estimates of travel time

\begin{tabular}{lcc}
\hline Variables & B & Sig. \\
\hline Number of Ride-sourcing apps owned & -0.516 & 0.045 \\
Charges Incurred (Thousand Rupiah) $=<10$ (1 yes, 0 no $)$ & -3.337 & 0.000 \\
Charges Incurred (Thousand Rupiah) $=10-20$ (1 yes, 0 no) & -2.554 & 0.000 \\
Charges Incurred (Thousand Rupiah) $=20-30$ (1 yes, 0 no $)$ & -1.510 & 0.000 \\
Frequency per week = 1 (1 yes, 0 no) & 0.451 & 0.397 \\
Frequency per week = 2 (1 yes, 0 no) & -0.100 & 0.886 \\
Constant & 2.066 & 0.026 \\
\hline Chi-Square & & 44.557 \\
df & & 6 \\
Sig. & & 0.000 \\
Goodness-of-fit Hosmer \& Lemeshow & & 0.613 \\
Percent Correct & & 77.2 \\
-2LogLikelihood & & 204.55 \\
Cox \& Snell R-square & 0.198 \\
Nagelkerke R-square & & 0.279 \\
\hline
\end{tabular}

Besides the statistics, parameter estimates reveal significant variables that is influencing the travel time using ride-sourcing. It is interesting to notice the variable of charges appear as the significant variable. The higher the charges, the less the travel time will be. It seems understandable that users have a high concern on travel cost. It also have a close relation with preference data, where the cost of ride-sourcing has higher similarity with conventional public transportation.

The other significant variable is the number of apps owned by users. It has a negative influence to the travel time. The more apps the users owned, the shorter the trip becomes. It seems as make sense. When a user has more than one app, it provides the user with more options when ordering a ride. If one app shows longer predicted waiting time than the others, the user is able to alter and select another provider which is closer.

Another finding is the variable of trip frequency. Even it has not significant influence in the model, the finding shows an interesting point. In one side, the variable has a negative influence which means travelers with more frequent trips tend to spend shorter travel time. It is understandable to know this finding. On the other side, users who travel once per week tend to travel longer. It is also easy to understand, as less frequent people will have a higher preference to travel longer or to reach more destinations as a way to reduce number of trip.

\subsection{Model estimation with socio-demographic variables}

In order to explore the role of sociodemographic variables to the dependent variable, a model with several sociodemographic variables was estimated. Table 4 provides the result of parameters estimates. The estimated model has a chi-square value of 52.714 and very small p-value. It implies that incorporating independent variables help improve the model. The result of the goodness-of-fit Hosmer \& Lemeshow test shows a value of 0.052 , just above 0.05 , which supports the idea that independent variables improve the model. This model has a similar percent correct with previous model, namely as much as $77.7 \%$. The values of Cox \& Snell R-square and Nagelkerke R-square are 0.230 and 0.323 , respectively. Thus, it can be judged that incorporating sociodemographic variables slightly improve the model. It can also be said that both models are able to explain the dependent variable. 
Table 4. Parameter estimates of travel time with sociodemographic variables

\begin{tabular}{lrc}
\hline Variables & \multicolumn{1}{c}{ B } & \multicolumn{1}{c}{ Sig. } \\
\hline Number of Ride-sourcing apps owned & -0.378 & 0.193 \\
Charges Incurred (Thousand Rupiah) $=<10$ (1 yes, 0 no) & -3.630 & 0.000 \\
Charges Incurred (Thousand Rupiah) $=10-20$ (1 yes, 0 no) & -2.906 & 0.000 \\
Charges Incurred (Thousand Rupiah)= 20-30 (1 yes, 0 no) & -1.796 & 0.004 \\
Frequency per week = 1 (1 yes, 0 no) & 0.252 & 0.640 \\
Frequency per week = 2 (1 yes, 0 no) & -0.428 & 0.543 \\
Age & 0.019 & 0.203 \\
Basic Education Level (1 yes, 0 no) & -0.674 & 0.328 \\
Intermediate Education Level (1 yes, 0 no) & 0.259 & 0.541 \\
Family Income & -0.259 & 0.046 \\
Constant & 2.178 & 0.107 \\
\hline Chi-Square & & 52.714 \\
df & & 10 \\
Sig. & & 0.000 \\
Goodness-of-fit Hosmer \& Lemeshow & & 0.052 \\
Percent Correct & & 77.7 \\
-2LogLikelihood & & 196.40 \\
Cox \& Snell R-square & & 0.230 \\
Nagelkerke R-square & & 0.324 \\
\hline
\end{tabular}

This second model supports previous finding, namely charges incurred has a significant negative influence. This finding is also support by another variable, namely monthly income. People with small monthly income tend to use ride-sourcing more which is explained by longer travel time. It is possible to have a far location but less frequent as their home location is far from the destination. In the same time this variable show that people with high income are not a big fan of ride-sourcing.

Furthermore, different with previous model, the variable of number of owned application becomes not significant in this second model. It is interesting to know that both models have similar estimation result. Variables of frequency of usage, age of users, and education level are found as not significant. The model shows that the older the users are, the longer the trips become. In the aspect of education, users with higher education level tend to travel longer.

\subsection{Discussion}

In one side, Medeiros et al. [17] stated that there is high similarity between conventional and smartphone-based ojek trips. It represents the long and strong relationship between the social and the technical aspects [19]. The main different is in the way they arrange the travel, i.e. the way to find information and booking. On the other side, even though there is similarities between conventional taxi and ride-sourcing, Rayle et al. [22] stated that the two have different in user characteristics, wait times, and trips served. This statement is in line with the result of this study.

It can be inferred from data that the growing existence of application-based-modes of transport does not automatically change people's behavior in travel. Data revealed a fact that only around $40 \%$ of respondents have an experience in using ride-sourcing. Even it is easy and almost free to use application, but it does not guarantee people will directly use the service. Moreover, it is also found that the users without any apps in their smartphone are still possible to use the service with the help of others who have the application to book the service. 
Two estimated models show the role of travel charges incurred in using ride-sourcing. The users put travel cost as an important aspect to be considered and will adjust their travel behavior by selecting closer location, shorter travel trip, or reduce the frequency. The traveler will adjust their decision by selecting shorter travel time or selecting operator which is able to provide shorter waiting time. It is only possible when users install more than one application and make them possible to compare the service.

The model shows the role of sociodemographic variable to travelers' decision. The variable of monthly income shows a negative influence which implies two things. Firstly, it reveals a low preference of people with high income to travel using ride-sourcing. Secondly, it is known that people with small monthly income tend to travel longer.

These findings reveal a fact that ride-sourcing' users have similar consideration with common travelers, i.e. conventional public transport users. They evaluate the trip based on fare and time as a logical effort to maximize their utility. An example is provided by Hsiao [20], where the decision to purchase online has a reason that shopping trip produces higher cost than bearing waiting for product delivery in online shopping.

The unique finding from this piece of study is the role of application. The number of applications owned by users provides benefit, namely users can compare services provided by different operators. This benefit is in agreement with the intended outcome of application, namely to provide an experience of easier way to arrange travel. It is in line with finding of Joewono et al. [14] that the degree of technology exposure will determine people's travel behavior.

\section{Conclusion}

This article reports the result of study about the usage of application (smartphone)-basedtransport, or well known as ride-sourcing, from the experience of users in Bandung, Indonesia. This study tries to fill the knowledge gap in the field of travel behavior, especially in investigating the impact of ICT to the dynamic of travel behavior. Empirical evidence from developing countries is another value provided by this study.

Results show the role of ICT to shoppers in reaching destination in Bandung. It is found that only around $40 \%$ of respondents have an experience in using ride-sourcing, where most of the users do not use ride-sourcing as the main mode of transport. The service is treated as additional service only. This small proportion of usage is similar with the finding of Medeiros et al. [17], where the total share of ojeg users is small [18] and the users of smartphone-based ojek are also users of private cars and motorcycle. Similar finding is found in Pittsburgh region that ride-sourcing is still a relatively small number of daily trips in an urban area [21].

The general motivation of people when selecting way of travel is still applicable when people evaluate this service. People still made an evaluation according to travel cost and travel time. These two classical variables are also found as significant in determining travel behavior of users in reaching shopping location. Data supports this inference as users experiencing the overwhelming characteristics of ride-sourcing, namely short waiting times.

Even this study is in very early stage, it provides several interesting findings. Thus, further study shows its potential. Comparison study regarding the topic of ride-sourcing from different point of view, i.e. different country, city, or background become an interesting and useful. Inclusion of travelers' perception is also another topic for further study. Efforts to understand the market is also important in the competing market between smartphone-based -transport and existing public transport. Furthermore, as suggested by Harding et al. [15], the application-based transport mode should mitigating the problems associated with market. Further elaboration from the point of view of transport policy in developing countries becomes important to provide better and more suitable public transportation service and environment. 


\section{Acknowledgement}

This study is fully sponsored by The Directorate of Research and Community Services, Directorate General of Research and Development Strengthening, The Ministry of Research, Technology, \& Higher Education, Republic of Indonesia according to Research Contract Number 1598/K4/KM/2017. The author thanks to all parties who have participated in data collection.

\section{References}

1. A. Santos, N. McGuckin, H. Y. Nakamoto, D. Gray, S. Liss. Summary of Travel Trends: 2009 National Household Travel Survey. (Federal Highway Administration, Washington DC, 2009)

2. H. Zulqarnain, A. U. Zafar, M. Shahzad. Factors that Affect the Choice of Consumers in Selecting Retail Store, for Grocery Shopping. International Journal of Multidisciplinary and Current Research. 3 (2015)

3. S. Farag, K. J. Krizek, M. Dijst. E-shopping and its Relationship with In-store Shopping: Empricial Evidence from the Netherlands and the USA. Transportation Reviews 26. 1. 43-61 (2006)

4. P. L. Mokhtarian. A Conceptual Analysis of the Transportation Impacts of B2C eCommerce. Transportation 31, 3. 257-284 (2004).

5. The World Bank Group. How ICTS Can Help Transport Systems Evolve. http://www.worldbank.org/en/news/feature/2015/05/14/information-andcommunication-technologies-facilitate-the-evolution-of-transport-systems. (2015).

6. P. L. Mokhtarian. A Typology of Relationships between Telecommunications and Transportation. (University of California Transportation Center, University of California Davis, Davis. 2009)

7. L. Rayle, S. Shaheen, N. Chan, D. Dai, R. Cervero. App-Based, On-Demand Ride Services: Comparing Taxi and Ridesourcing Trips and User Characteristics in San Francisco. (University of California Berkeley, Berkeley. (2014).

8. M. Dawes. Perspectives on the Ridesourcing Revolution: Surveying Individual Attitudes toward Uber and Lyft to Inform Urban Transportation Policymaking. (Department of Urban Studies and Planning. Massachusetts Institute of Technology, Cambridge. 2015)

9. N. J. Farin, M. N. A. Ali Rimon, S. Momen, M. S. Uddin, N. Mansoor. A Framework for Dynamic Vehicle Pooling and Ride-Sharing System. (Conference: International Workshop on Computational Intelligence (IWCI) 2016.)

10. R. Rahayu, J. Day. Determinant Factors of E-Commerce Adoption by SMEs in Developing Country: Evidence from Indonesia. Procedia Social and Behavioral Sciences. 195. 142-150. (2015)

11. Badan Pusat Statistik Kota Bandung. Statistik Daerah Kota Bandung. (2016)

12. T. B. Joewono. Interaksi ICT, Perjalanan Berbelanja, dan Penggunaan Angkutan Publik. Laporan Penelitian Unggulan Perguruan Tinggi. Bandung. (2017).

13. J. Kumar. Karakteristik Penggunaan Ridesourcing Dalam Perjalanan Berbelanja Di Kota Bandung. Bachelor Thesis, Department of Civil Engineering. Parahyangan Catholic University. Bandung (2018).

14. T.B. Joewono, B.A. Effendi, H.S.A. Gultom, R.P. Rajagukguk, Influence of Personal Banking Behavior to the Usage of Electronic Card for Toll Payment, Transportation Research Procedia 25C, 4458-4475 (2017) 
15. S. Harding, M. Kandlikar, S. Gulati. Taxi apps, regulation, and the market for taxi journeys. Transportation Research Part A 88, 15-25 (2016).

16. Y.O. Susilo, T.B. Joewono, Indonesia, in D. Pojani, and D. Stead, (Eds.) The Urban Transport Crisis in Emerging Economies, Springer International Publishing Switzerland (2017)

17. R.M. Medeiros, F. Duarte, F. Achmad, A. Jalali, Merging ICT and informal transport in Jakarta's ojek system, Transportation Planning and Technology 41,3, 336-352 (2018)

18. Y.O. Susilo, T.B. Joewono, W. Santosa, and D. Parikesit, A Reflection of Motorization and Public Transport in Jakarta Metropolitan Area. IATSS Research 31, 1: 59-68 (2007)

19. W. Bijker, About Bicycles, Bakelite and Bulbs: Towards a Theory of Sociotechnical Change. Cambridge, MA: MIT Press. (1995)

20. M. Hsiao, Shopping mode choice: physical store shopping versus e-shopping. Transportation Research Part E 45, 86-95 (2009)

21. Z. Chen, Impact of Ride-Sourcing Services on Travel Habits and Transportation Planning. Bachelor Thesis of Transportation Engineering, Beijing Jiaotong University, 2013

22. L. Rayle, D. Dai, N. Chan, R. Cervero, and S. Shaheen, Just a better taxi? A surveybased comparison of taxis, transit, and ridesourcing services in San Francisco. Transport Policy 45, 168-178 (2016)

23. W.W. Recker, L.P. Kostyniuk, Factors influencing destination choice for the urban grocery shopping trip. Transportation 7, 19-33 (1978) 